\title{
COMPARATIVE ANALYSIS OF FUELS DERIVED FROM PE PLASTIC WASTE WITH A MIXTURE OF PLASTIC RECYCLING WASTE OF CODES: 1, 2, 4, 5, 6 AND 7 BASED ON LOW-TEMPERATURE PYROLYSIS
}

\author{
Anna Lesnau, Mirosław Tyliszczak \\ Gdynia Maritime University, Department of Mechanical Engineering \\ Morska Street 81-87, 81-225 Gdynia, Poland \\ tel.: $+48603499554,+48781028810$ \\ e-mail:a.lesnau@wm.umg.edu.pl,m.tyliszczak@wm.umg.edu.pl
}

\begin{abstract}
Thanks to their numerous advantages, plastics are becoming more and more widely used in all branches of industry. The quantities of products, their packaging and, consequently, the amount of synthetic polymer waste are steadily increasing, what poses a high risk to the environment due to their long decomposition time. To reduce waste production is practically impossible, therefore it is very important to constantly implement new and improve existing methods of waste treatment. The following article presents one of the alternative methods for synthetic polymer waste treatment, which is low-temperature pyrolysis. Two pyrolysis processes were carried out. During the first experiment a polyethylene plastic material was used, in the second experiment a mixture of typical household recycling waste of codes 1, 2, 4, 5, 6, and 7 were tested. During the thermal processing, the input material undergoes a chemical transformation due to breaking of long hydrocarbon chains. At the same time, high-energy density products, such as petroleum products and gas, are produced. The main advantage of the presented method is that it allows reducing preliminary technological processes to a minimum and it is easily automated, as it reduces the process to one compact installation. The reduction of the amount of stored waste and the recovery of petroleum derivatives, are additional advantages of pyrolysis implementation. That, in consequence allows reducing consumption of fossil fuel resources.
\end{abstract}

Keywords: pyrolysis, plastics, waste

\section{Research on the topic - an overview}

Due to the deepening fossil fuel crisis and waste management problems, scientists and authorities face the challenge of addressing the issue of alternative energy sources. The main alternative energy sources are biomass, hydro, geothermal, wind, solar and nuclear energy. However, these solutions can replace fossil fuels only to some extent. The management of waste, which is increasing year by year, is another problem to be addressed.

According to Polish Central Statistical Office (GUS), in 2016 over 11.6 million tons of municipal waste was collected in Poland, which is $7.3 \%$ more than in the year 2015. On average, 303 kilograms of waste per person were produced. The largest amount of waste was collected in the following voivodships: Dolnośląskie $-361 \mathrm{~kg}$, Zachodniopomorskie and Śląskie $-355 \mathrm{~kg}$, Lubuskie - $346 \mathrm{~kg}$. The smallest amount of waste was collected in the voivodships of Świętokrzyskie - $184 \mathrm{~kg}$, Lubelskie - $196 \mathrm{~kg}$, and Podkarpackie - $210 \mathrm{~kg}$. It can be estimated that the average content of waste in a mixed municipal stream ranges from $16.7 \%$ in the city centre to about $12 \%$ in single-family housing.

Thus, the main task for the municipal authorities is to develop a well thought-out management of resources derived from plastic waste. For many years, the industry has been busy developing technologies for segregation, recycling and reuse of materials. From the waste collection, through the transportation, sorting, and processing on site, hundreds of different solutions are working in service of minimising the quantity of waste that would be dumped. Although waste recycling and 
management systems are more and more efficient, there is often a high quantity of calorific solid waste that cannot be recycled with available measures. Pyrolysis is the thermochemical decomposition of organic material at high temperature and in absence of oxygen or inert gases atmosphere. Nowadays, pyrolysis is getting attention for its flexibility to generate a combination of solid, liquid and gaseous products in different proportions just by the variation of operating parameters such as temperature or heating rate. It also gives possibility to transforms materials of low-energy density into bio-fuels of high-energy density and recovers higher value chemicals. Different types of pyrolysis have been developed: fast, catalytic fast, intermediate, slow, vacuum. Moreover, different types of reactors have been investigated. One of the great advantages of this process is that many types of raw material can be used, including industrial and domestic residues. The fractions of MSW subjected to pyrolysis mainly include food waste, paper, cloth, plastics, and yard waste. It is then easy to understand the high variability of conditions and consequently of residues obtainable. Prerequisite for pyrolysis successful application is the appropriate choice of input materials and setting of optimal process conditions. For these reasons, suitability or unsuitability of selected types of waste and their mixtures for the pyrolysis process was verified by laboratory experiments many times with subsequent assessment of the quantity and quality of the individual products of pyrolysis.

Many articles have been written on the topic, focusing mainly on biomass pyrolysis, while the subject of pyrolysis of mixed plastic waste is practically untouched. Authorities seek to resolve this problem by issuing appropriate legal solutions. The basic assumption of the Directive 2008/98/EC on waste is to create legal regulations to promote the idea of recycling to limit the production of waste and to utilize waste as a material and fuel resource.

Scientists who take up this challenge are to face many uncertainties. The main variables of the pyrolysis process are temperature and the type of feedstock used. Dehydrated plastics from PS, PP, and PE groups are mainly used in pyrolysis. Such treatment of other groups of plastics, used individually, does not bring any positive effects. Thus, in the present article we focus on the comparison of two fuel samples obtained in the process of low-temperature pyrolysis of plastic waste.

\section{Description of the pyrolysis process - research methodology}

In order to carry out the experiment, two fuel samples were produced. One of the commonly used polymers from PE group was used during the first low-temperature pyrolysis process. A blend of waste from different polymer groups (HD-PE, LD-PE, PP, PET, paper, aluminium, food residues) was used as the second input material. The feedstock was subjected to medium pressure pyrolysis with direct cooling as shown in Fig. 2.

The main elements of the low-temperature pyrolysis reactor unit are:

- a 20 litre reaction chamber with thermal insulation,

- a LPG gas burner with heating power of $12 \mathrm{~kW}$,

- a vapour cooling system (a water cooler with gas and oil products drain),

- a control cabinet which allows to set the optimal process temperature in the system.

\section{Preparation of the input material}

The article summary assumes that plastic waste is fed directly into the reactor. However, the input material should be deprived of air (e.g. in closed plastic bottles), which adversely affects the process. Properly prepared feedstock should be crushed, preferably into pieces of up to $5 \mathrm{~cm}$ in length and deprived of water. Dry food residues do not have a negative effect on pyrolysis, so there is no need additionally to clean the input. For the first sample, waste made of plastics from group 02 (HD-PE) was used, and for the second sample, waste from all groups of plastics available on the market (HD-PE, LD-PE, PP, PS, PET, paper, aluminium, etc.) was used. 
Photos of the waste utilized in the process are shown in Fig. 1.
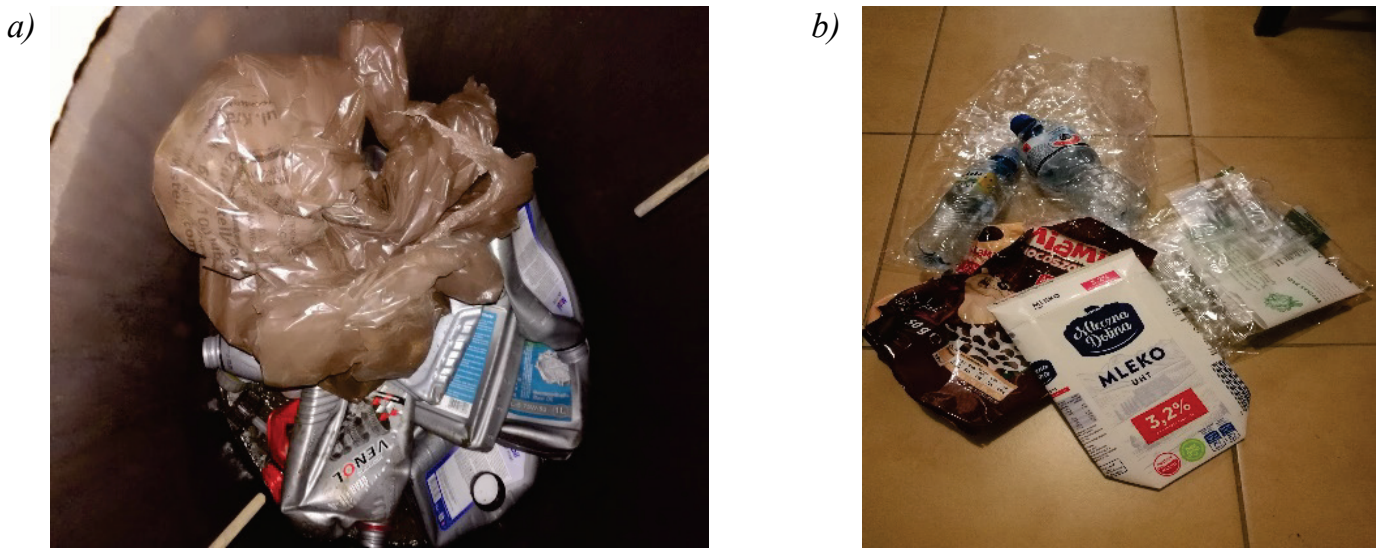

Fig. 1. Batch: a) PE group plastics, b) mixed waste

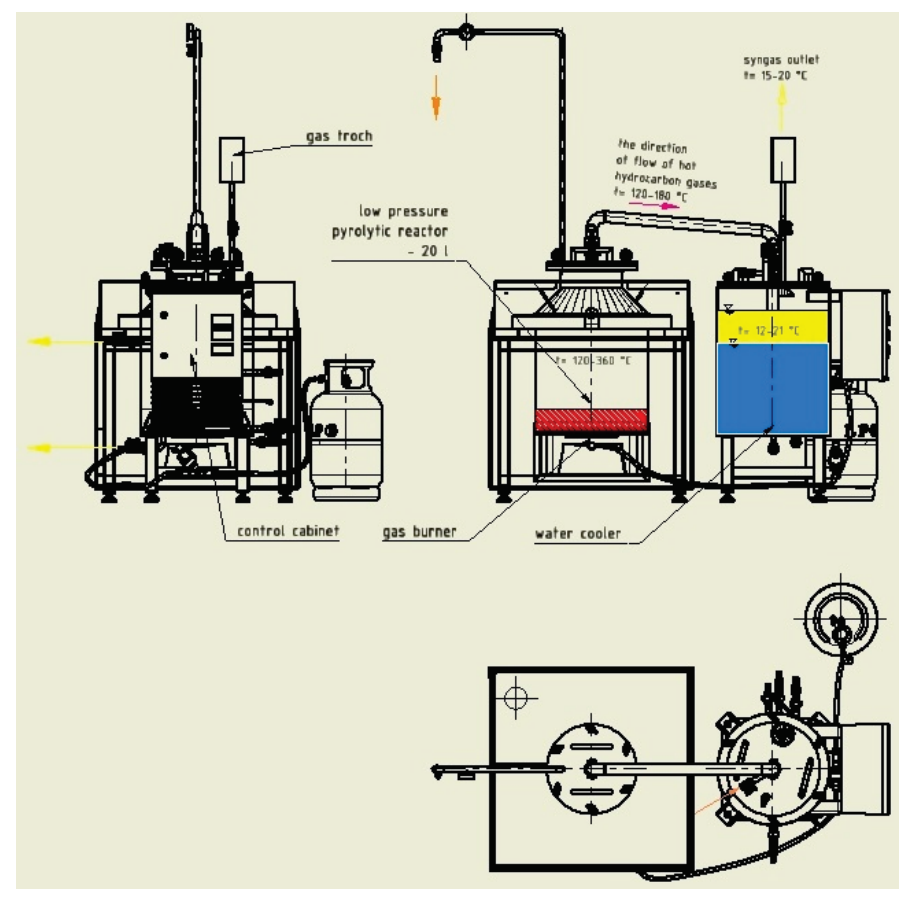

Fig. 2. Reactor technological diagram

\section{Description of the process}

After the input material had been prepared, we proceeded to the next stage of the process. The input material was placed in the reactor and sealed tightly. The burner, as well as the control and automation system was started. During the first phase, the reactor is heated to a suitable temperature of hydrocarbon vapours within the range of $240-250^{\circ} \mathrm{C}$. Further, the so-called hydrocarbon steam is directed to the cooling system. In the experiment, the water cooler was used where the steam is cooled directly in the water of the cooling unit. Due to the fact that water and oil differ in density, oil accumulates above the surface of the water, where the excess is drained and then directed to a separate oil tank. The vapour and gas cooling system is additionally cooled to keep the temperature constant. Gases and hydrocarbon vapours must overcome pressures higher than atmospheric pressure due to the level of the water column in the cooling system. Altering this level leads to alterations in the physical and chemical characteristics of the product obtained. Higher pressure resulted in obtaining pyrolytic oil with physical and chemical properties similar to those of gasoline. 
During the pyrolysis of plastics, a certain amount of combustible gases mixture is produced, which is burned in the gas torch of the cooling system. The amount of produced gas is correlated with the temperature of the process.

\section{Completion of the process}

The lack of a characteristic bubbling sound in the cooling unit and the high temperature (around $360^{\circ} \mathrm{C}$ ) of the hydrocarbon vapour in the upper part of the reactor signals that the process has ended.

After the process was completed, the heating system was stopped, thus lowering the temperature of the reactor. For safety reasons, it is not recommended to open a hot reactor, as there is a risk of scalding by the remains of the produced hydrocarbon vapour. The discharge valve on the cooling unit discharges the produced pyrolysis oil into a separate container.

The system can be restarted after it has cooled down completely.

\section{Alternative fuels obtained}

Two different fuel samples were obtained as a result of the experiment. Both pyrolysis processes were carried out under the same conditions, i.e. at the temperature of hydrocarbon vapours of $240-250^{\circ} \mathrm{C}$, within process time of about 4 hours, with the input material weight of $1 \mathrm{~kg}$.
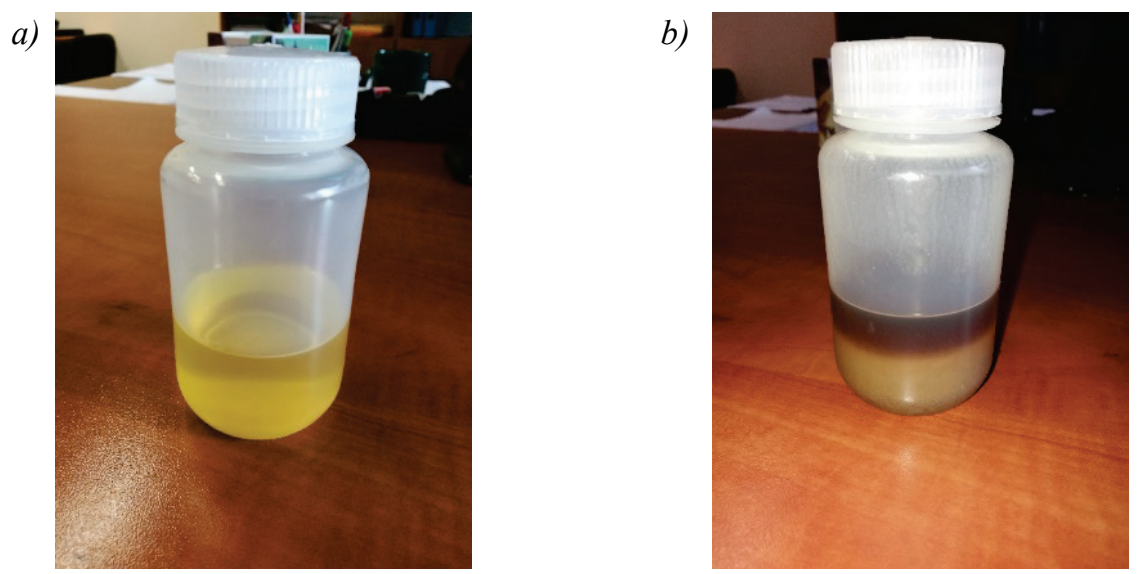

Fig. 3. Received fuel samples: a) fuel obtained from Group 2 HD-PE plastics, b) fuel obtained from a mixture of different polymer groups

Due to the high contamination of sample B, it was necessary to perform a filtration process, for which a laboratory filter paper was used.

The samples were tested for their calorific value, density and viscosity. We tested $0.50 \mathrm{~g}$ of each sample (Fig. 4). The calorific value was measured in the calorimeter IKA C 600. Fuel density was measured with the use of an oscillating density meter DA-640 (Fig. 5). Viscosity measurement was performed with HAAKE MARS rotational rheometer (Fig. 6).

\section{Results}

The polymer waste was subjected to low-temperature pyrolysis in order to obtain mainly oil and gas products, which could prove to be an alternative to fuels.

The waste input in both cases was 1 kilogram. The process of pyrolysis of plastics from HD-PE group 2 allowed obtaining about $0.85 \mathrm{~kg}$ of fuel. In the second pyrolysis of mixture of plastic waste only $0.1 \mathrm{~kg}$ of fuel was obtained. Such small amount of oil products could probably be correlated with specifics of multi-material waste (milk or juice packaging) and PET type waste. 


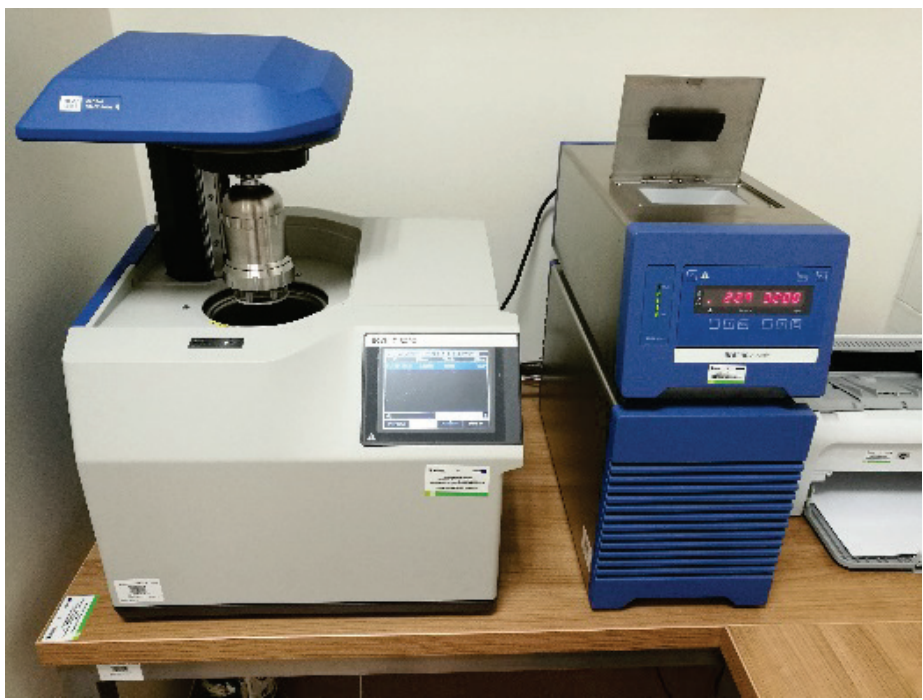

Fig. 4. IKA C 600 calorimeter

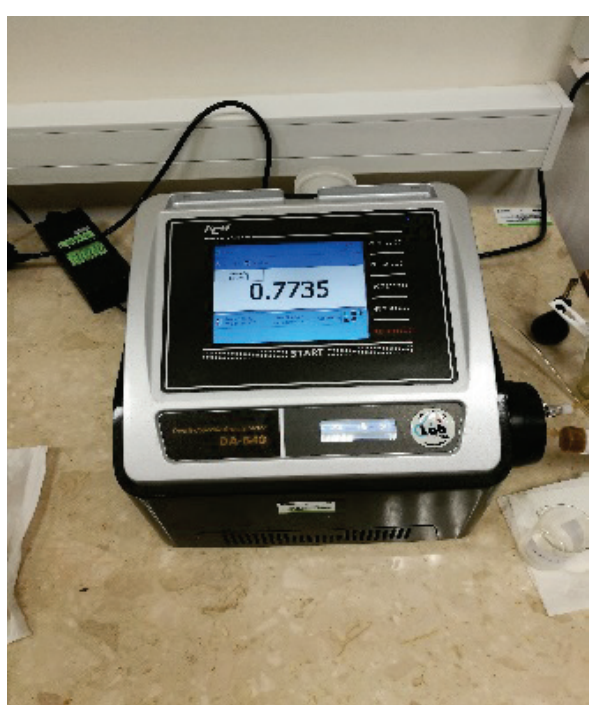

Fig. 5. DA-640 oscillatory density meter

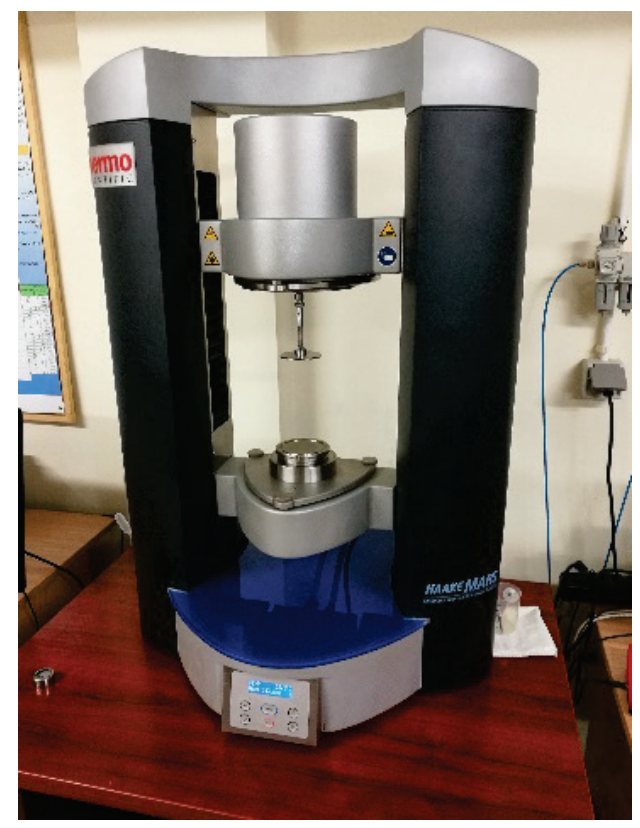

Fig. 6. HAAKE MARS rotational rheometer

Analysis of both types of fuels shows that the calorific value of both fuels is comparable and similar to the properties of petroleum products, e.g. petrol. However, due to the low viscosity coefficient, it is recommended to utilize obtained fuel only for process maintenance or heating purposes, but not for propulsion purposes, e.g. for powering piston engines.

The table below presents the results of the tests carried out.

Tab. 1. Results of tests performed

\begin{tabular}{|l|c|c|}
\hline & Sample A & Sample B \\
\hline Heating value $[\mathrm{J} / \mathrm{g}]$ & 46143 & 45369 \\
\hline Density temp. $20^{\circ} \mathrm{C}\left[\mathrm{g} / \mathrm{cm}^{3}\right]$ & 0.7471 & 0.7897 \\
\hline Density temp. $40^{\circ} \mathrm{C}\left[\mathrm{g} / \mathrm{cm}^{3}\right]$ & 0.7300 & 0.7699 \\
\hline Viscosity temp. $20^{\circ} \mathrm{C}[\mathrm{mPas}]$ & 0.65 & 7.85 \\
\hline Viscosity temp. $40^{\circ} \mathrm{C}[\mathrm{mPas}]$ & 0.48 & 1.15 \\
\hline
\end{tabular}




\section{Conclusions}

In the present article, we discussed the results of pyrolysis of one group of plastic waste and a pyrolysis of a mixture of other plastics. It has been shown that the final properties of the obtained products (oil and gas) are strongly correlated with the proper segregation and preparation of input material. Low-temperature pyrolysis should be conducted separately for each group of waste. This would allow standardizing the process and selecting the appropriate technology.

The main technological problem posed by pyrolytic oils is the large amount of dissolved volatile hydrocarbons and the content of carcinogenic substances. Appropriate technology should enable their removal so that safe operating conditions and their storage can be ensured.

Pyrolysis is an effective process of processing plastic waste, but unfortunately, it is profitable only for selected branches of industry. Compared to other methods of waste disposal, pyrolysis of plastics is distinguished by the fact that there is a possibility of partial recovery of oil and gas, which can be reused. In this type of waste treatment, no harmful chemical compounds are released, as is the case of a waste from an incineration plant.

Taking into account advantages and disadvantages of pyrolysis, it can be concluded that, despite the large financial outlays and the complex technology, it is worthwhile to devote time to the development of this method and make further attempts to process plastic waste from all groups, and not only from selected groups.

\section{References}

[1] Przybylski, M., GUS: polacy produkuja coraz więcej śmieci, http://www.pap.pl/aktualnosci/ news, 115082olacy-produkuja-coraz-wiecej-smieci.html.

[2] Czop, M., Kompleksowe zagospodarowanie tworzyw sztucznych ze strumienia odpadów komunalnych. Aktualne zagadnienia w inżynierii środowiska, red. Krzysztof Barbusiński, Politechnika Śląska. Wydział Inżynierii Środowiska i Energetyki, Gliwice 2015.

[3] Dyrektywa Parlamentu Europejskiego i Rady 2008/98/WE z dnia 19 listopada 2008r. W sprawie odpadów oraz uchylająca niektóre dyrektywy.

[4] Plastics industry in Poland, 2013.

[5] Chowdhury, R., Sarkar, A., Reaction kinetics and product distribution of slow pyrolysis of Indian textile wastes, International Journal of Chemical Reactor Engineering, Vol. 10, Iss. 1, 2012.

[6] Biswal, B., Kumar, S., Singh, R. K., Production of hydrocarbon liquid by thermal pyrolysis of paper cup waste, Journal of Waste Management, pp. 1-7, 2013.

[7] Grycova, B., Stepkova, K., Kuca, R., Fiedor, J., Obrucka, K., Application of pyrolysis process in the processing of food waste, Polish Journal of Chemical Technology, Vol. 18, Iss. 1, pp. 19-23, 2016.

Manuscript received 02 August 2019; approved for printing 05 December 2019 